\title{
Treatment: Guidelines
}

\section{Treatment Guidelines for Substance Use Disorders and Serious Mental Illnesses: Do They Address Co-Occurring Disorders?}

\author{
BRIAN E. PERRON,${ }^{1}$ ALICIA BUNGER, ${ }^{2}$ \\ KIMBERLY BENDER, ${ }^{3}$ MICHAEL G. VAUGHN ${ }^{4}$ AND \\ MATTHEW O. HOWARD ${ }^{5}$ \\ ${ }^{1}$ University of Michigan, School of Social Work, Ann Arbor, MI USA \\ ${ }^{2}$ Washington University, St. Louis, MO USA \\ ${ }^{3}$ University of Denver, Graduate School of Social Work, Denver, CO USA \\ ${ }^{4}$ Saint Louis University, School of Social Work, Public Policy, Department of \\ Community Health, Division of Epidemiology, St. Louis, MO USA \\ ${ }^{5}$ Professor, School of Social Work, University of North Carolina, Chapel Hill, \\ NC USA
}

\begin{abstract}
Practice guidelines are important tools for improving the delivery of evidence-based practices and reducing inappropriate variation in current treatment approaches. This study examined the degree to which guidelines targeted to the treatment of substance use disorders or serious mental illness address treatment of co-occurring disorders. Guidelines archived by the National Guideline Clearinghouse (NGC) were retrieved in December 2007 and content analyzed. Nineteen pertinent guidelines were identified, and 11 included recommendations regarding the assessment and/or treatment of cooccurring disorders. None of the guidelines making recommendations for treatment of co-occurring disorders included outcomes that clearly targeted both substance use and mental health disorders. Limitations and implications of this study are noted.
\end{abstract}

Keywords treatment guidelines; dual diagnosis; co-occurring disorders

\section{Introduction}

Substance use disorders (SUDs) and serious mental illnesses (SMIs) are significant public health concerns. Approximately 22 million people in the United States were classified with substance use or dependence in the past year (Epstein, Barker, Vorburger, and Murtha, 2004) and 44 million people have experienced a SMI within the past year (National Institute of Mental Health, 2001; US Department of Health and Human Services, 1999). Furthermore,

Address correspondence to Brian E. Perron, School of Social Work, University of Michigan, 1080 S. University Avenue, Ann Arbor, MI 48109. E-mail: beperron@umich.edu. 
the Substance Abuse and Mental Health Services Administration (SAMHSA) estimated in 1997 that the United States expended roughly $\$ 85$ billion for these disorders, and $56 \%$ of this amount was from public sources in that year alone (Mark, 2003; Mark et al., 2000).

Substance use disorders and serious mental illnesses frequently co-occur. According to the US Surgeon General, 41 to $65 \%$ of persons with a lifetime SUD also have a history of at least one SMI, and approximately $50 \%$ of persons with a lifetime SMI also have a lifetime history of at least one SUD (US Department of Health and Human Services, 1999). Therefore, a maxim of contemporary epidemiological and services research is that co-occurring disorders (also referred to as "comorbidity" and "dual diagnosis") are the rule rather than the exception (Stinson et al., 2005).

According to Drake and colleagues (2001), staged interventions, assertive outreach, motivational interventions, counseling, social support, a long-term perspective, comprehensiveness, and cultural sensitivity and competency are the key components of effective treatment for co-occurring disorders. Despite evidence that existing treatment approaches can be effective (Brunette, Mueser, and Drake, 2004; Drake, Mercer-McFadden, Cueser, McHugo, and Bond, 1998; Drake, Mueser, Brunette, and McHugo, 2004; Dumaine, 2003; RachBeisel, Scott, and Dixon, 1990), only a small percentage of people with co-occurring disorders receive effective treatment that addresses both disorders (Substance Abuse and Mental Health Services Administration, 2002; Watkins, Burnam, Kung, and Paddock, 2001). This lamentable state of affairs may be attributable to the absence of brief screening instruments (Lincoln, Liebschutz, Chernoff, Nguyen, and Amaro, 2006; Swartz and Lurigio, 2006), which are critical for recognizing and subsequently treating disorders. Services research has also documented limited availability of services targeting co-occurring disorders (Ducharme, Knudsen, and Roman, 2006; Watkins et al., 2001), and absence of training vis-à-vis assessment and treatment of comorbid conditions (Hall, Amodeo, Shaffer, and Vander Bilt, 2000). Given the high costs and deleterious consequences of co-occurring SUDs and SMIs, numerous governmental agencies have made quality improvement in this practice area a priority (National Advisory Mental Health Council, 1999; National Institute of Drug Abuse, 2003; President's New Freedom Commission on MentalHealth, 2002; US Department of Health and Human Services, 2000).

The emergence of translational research is a direct result of increased awareness of the pressing need to improve the system of care for dually diagnosed clients. Treatment guidelines are important components of broader strategies for moving research into practice and changing provider practice patterns (Grimshaw et al., 2001, 2004). Treatment guidelines are the systematically compiled statements of empirically tested knowledge and recommended practices designed to help practitioners and clients select appropriate interventions for specific clinical circumstances (Proctor and Rosen, 2003; Rosen and Proctor, 2003). A key function of guidelines is to promote effective decision-making in situations that are frequently encountered by service providers and their clients (Eddy, 1996). Clinical practice guidelines have received considerable attention in the literature on evidence-based practices and are one of the major tools for reducing treatment variability and translating research into practice (Howard and Jensen, 1999; Institute of Medicine, 2006; Rosen and Proctor, 2003; Walker, Howard, Lambert, and Suchinsky, 1994; Walker, Howard, Walker, Lambert, and Suchinsky, 1995).

\section{Research Objectives}

Using a public open-access database of treatment guidelines, this study examined the extent to which current guidelines targeting either SUDs or SMIs also addressed cooccurring disorders. Co-occurring disorders are associated with a wide range of problems 
requiring the attention of service providers from various disciplines. Therefore, this study also examined the outcomes and intended audience targeted in guidelines that address co-occurring SUDS and SMIs.

\section{Methods}

\section{Data Source}

This study examined guidelines archived by the National Guideline Clearinghouse (NGC; http://www.guidelines.gov/), which is a public, open-access database of treatment guidelines. The NGC is sponsored by the Agency for Healthcare Research and Quality (AHRQ) of the US Department of Health and Human Services. It was originally created by AHRQ in partnership with the American Medical Association and the American Association of Health Plans (now America's Health Insurance Plans). Advantages of this resource are that guidelines are presented in a standardized format, located in a single database, and freely available, thereby reducing the burden of searching for and retrieving guidelines. The NGC is the only coordinated effort to organize and disseminate practice guidelines in this fashion. This database also contains guidelines produced by the major health-related organizations, including the American Medical Association, the American Psychiatric Association, and the Department of Veterans Affairs. At the time of writing this report, the database included 2,264 guidelines.

\section{Search Definitions}

In this study, "substance use disorders" included abuse or dependence based on the criteria of the DSM-IV-TR (American Psychiatric Association, 2000). "Substances" of abuse were alcohol and those psychoactive drugs identified in DSM-IV-TR (Brunette et al., 2004). The specific SMIs targeted in this study were those associated with significant disability and that were widely prevalent and commonly treated within the public mental health system: schizophrenia-spectrum disorders, bipolar disorder, and major depression (Drake et al., 2001).

"Co-occurring disorders" referred to the simultaneous presentation of a substance use disorder and a serious mental illness. This usage is synonymous with other commonly used terms such as "dual diagnosis," "dual disorders," "co-morbidity," and "coexisting disorders."

\section{Search Procedures}

A computerized bibliographic search for guidelines of the NGC database was conducted on December 1, 2007. The NGC database does not provide the facilities to conduct complex searches containing Boolean operators. Thus, the procedure involved a broadbased search using the following key words: "substance abuse," "bipolar disorder," "depression," and "schizophrenia." This search procedure proved to be comprehensive. Specifically, it returned guidelines that were relevant to the study purpose and numerous guidelines that were irrelevant. The search strategy also returned a large number of duplicate guidelines. For example, the search for schizophrenia guidelines returned many depression guidelines. Subsequent searches using other synonymous keywords (e.g., major depressive disorder, psychosis, schizoaffective disorder, substance dependence, drug abuse) did not return additional unique guidelines. Finally, a search for guidelines targeting "co-occurring disorders" and its various synonyms (e.g., dual diagnosis, dual 
disorders, co-morbidity, and coexisting disorders) did not produce any additional unique guidelines.

A preliminary review indicated that the available guidelines for SUDs and SMIs were very heterogenous, targeting a variety of different populations and multiple disorders. In order to produce a set of guidelines that were comparable with respect to study aims, a set of inclusion and exclusion criteria was applied. Each criterion and the number of guidelines excluded at each step are summarized in Table 1. The criteria and justification are as follows. Guidelines were limited to adult treatment (age 17 to 44 years), given the prevalence of the disorders and treatment varies considerably with different age groups. Guidelines were excluded if they were not published by a US organization, since the system of care can largely determine the treatment possibilities. Guidelines were also excluded if they did not specifically address the target SUDs or SMIs as primary disorders. For example, guidelines were excluded that considered SUDs or SMIs as secondary conditions associated with other primary medical or social conditions (e.g., spinal cord injury, cardiovascular disease, and domestic violence). As this study focused on interdisciplinary guidelines, guidelines focusing specifically on medication management were also excluded from the review.

After excluding duplicate guidelines, the complete guidelines were downloaded as portable document files (PDFs) and reviewed. The full list of search results was compiled and the titles and summaries of each guideline were reviewed.

\section{Coding}

Guidelines were examined to determine whether they provided any treatment or screening recommendations regarding co-occurring disorders. Treatment recommendations included any clinical or psychosocial interventions specifically targeting co-occurring disorders. Screening recommendations included any diagnostic or assessment procedures for cooccurring disorders. Intended users of guidelines were categorized into two types: (1) medical professionals (physicians, nurses, advanced practice nurses, pharmacists, physician assistants, and other health care providers); (2) behavioral health clinicians (social workers, psychologists, other mental health professionals, and substance use disorder treatment providers). The different types of major outcomes targeted by each treatment guideline were recorded as written.

\section{Results}

\section{Recommendations for Co-Occurring Disorders}

A total of 19 unique treatment guidelines were retrieved from the NGC database; nine guidelines targeted SUDs and 10 targeted SMIs. These guidelines and their full citations are provided in Appendix. For purposes of brevity, guidelines cited in the text are referred to by the letter preceding the abbreviation in this Appendix.

Of the total guidelines, slightly more than half $(58 \%, N=11)$ contained at least one recommendation with respect to assessment and/or treatment of co-occurring disorders (see Table 2). While SMI guidelines had a higher proportion of co-occurring recommendations than SUD guidelines (64\% versus 55\%, respectively), these differences were not significant based on a Fisher's exact test $(p=.41)$. Bipolar disorder was the only type of disorder for which there were no guidelines containing recommendations for a co-occurring disorder. Across all guidelines that addressed co-occurring disorders, the most common recommendation was for screening/assessment, which was present in $64 \%(N=7)$ of the guidelines 


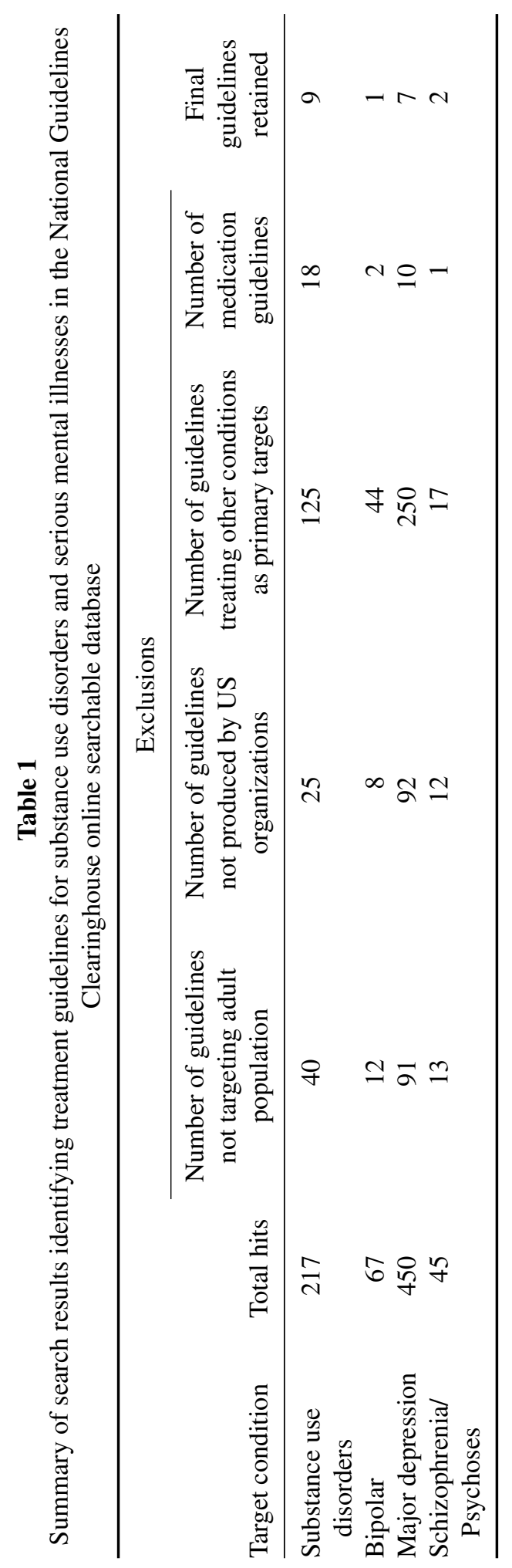




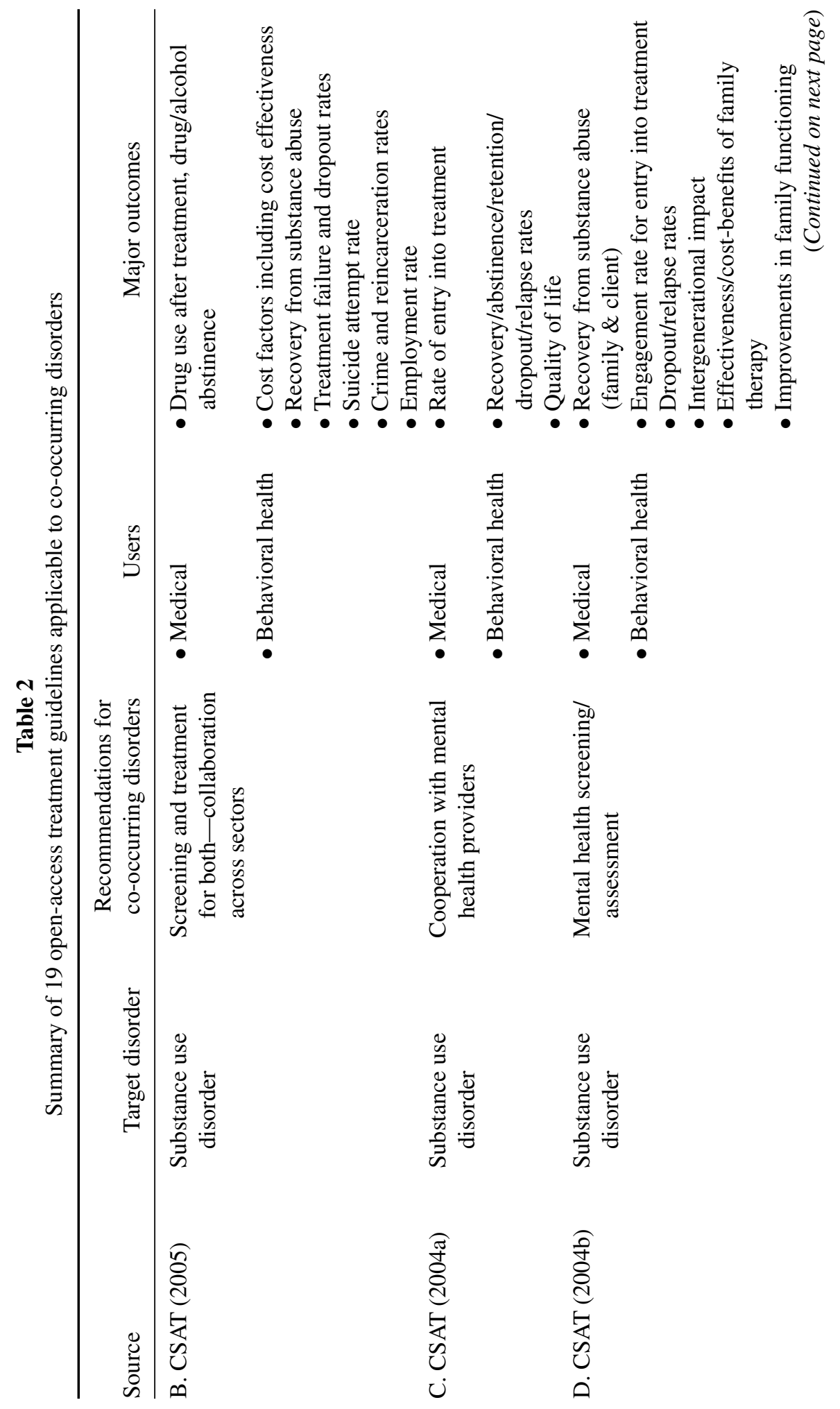




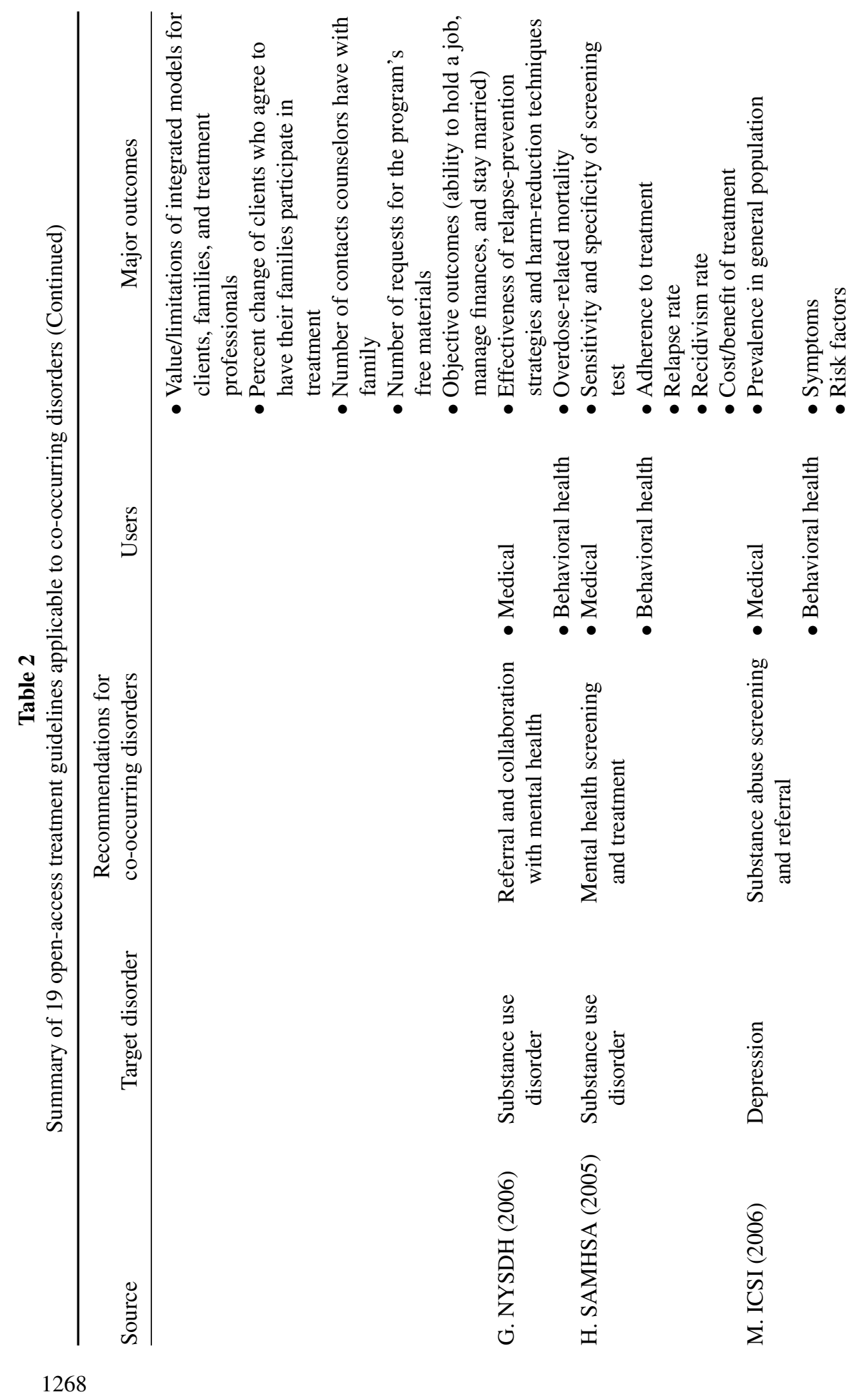



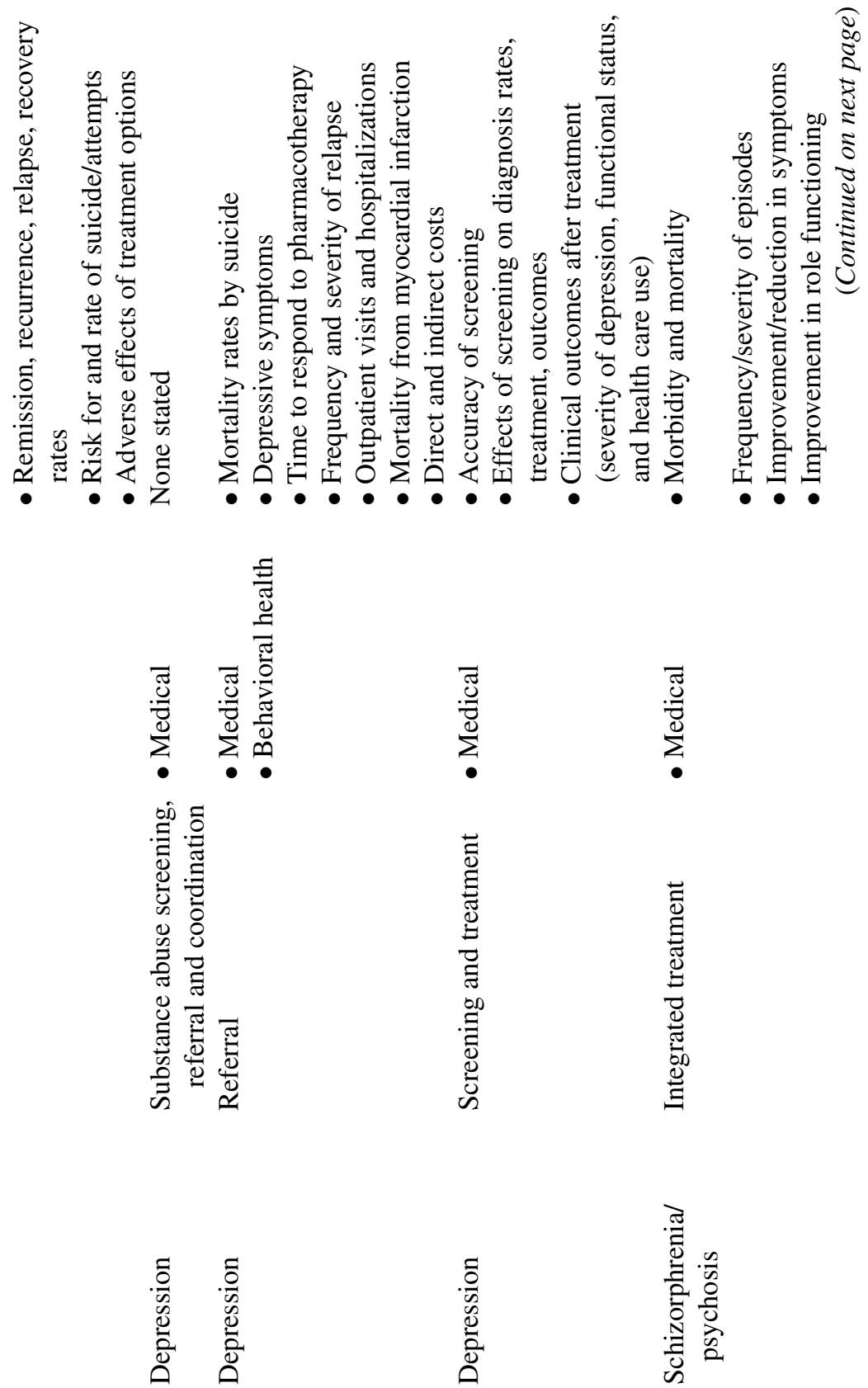

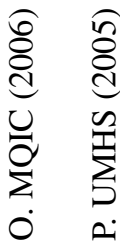

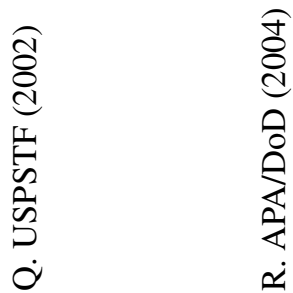




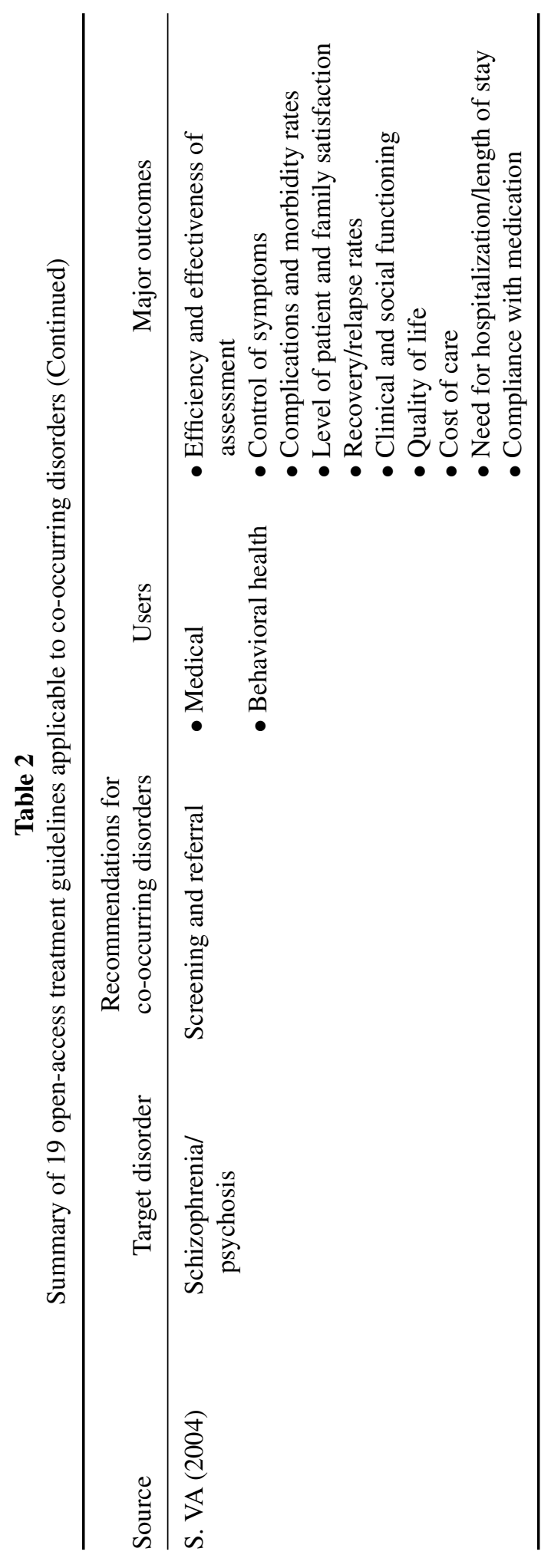


(Guidelines D, B, G, H, M, O, P, Q). Forty-five $(N=5)$ of the guidelines recommended a referral to a provider in the other (i.e., SUD or SMI) sector of care (Guidelines G, M, O, P, $\mathrm{R}$ ). Four guidelines recommended collaboration or cooperation across sectors (Guidelines C, B, G, O), and one guideline recommended integrated SUD and SMI treatment (Guideline R). It should be noted that two guidelines recommended "treatment" (Guidelines H, Q), but additional information was not specified in terms of how treatment should be conducted (e.g., collaboratively or in an integrated approach).

\section{Multidisciplinary Guidelines}

Medical professionals were the intended users of all 11 treatment guidelines that addressed co-occurring disorders. Of these 11 guidelines, all but three (Guidelines O, Q, R) also listed behavioral health professionals as intended users. Specifically, all guidelines for SUDs that included recommendations for co-occurring disorders targeted both medical and behavioral health providers. However, behavioral health providers were not listed as intended users on two SMI guidelines for depression guidelines (Guideline O, Q) and one SMI guideline for schizophrenia/psychosis (Guideline R).

\section{Treatment Outcomes}

With the exception of one (Guideline O), all guidelines listed treatment outcomes. The number of outcomes targeted in these guidelines containing recommendations for cooccurring disorders ranged from 3 to 11 (Mean = 5.9, SD = 3.0). Among this set of guidelines, there were no clear outcomes that addressed both psychiatric symptomatology and substance abuse-related outcomes, such as relapse. Three SMI guidelines that addressed co-occurring disorders in some fashion referred to relapse (Guidelines M, P, S) but did not indicate whether relapse referred to the SMI, SUD, or both. All guidelines that addressed co-occurring disorders and described treatment outcomes targeted at least one psychosocial outcome beyond clinical outcomes.

\section{Discussion}

This study reviewed the degree to which guidelines for SMIs and SUDs archived by the National Guidelines Clearinghouse addressed treatment for co-occurring disorders. Slightly more than half of the total guidelines retrieved included some type of recommendation for the treatment of co-occurring disorders. These recommendations included assessment, referrals, and collaboration with other professionals in the other sector of care. With the exception of two guidelines (described below), these recommendations contained minimal elaboration or specificity, leaving considerable room for interpretation on how the recommendations should actually be implemented in routine practice.

Two guidelines are particularly noteworthy with respect to their specificity regarding treatment for co-occurring disorders. This included the treatment guideline for schizophrenia, authored by the American Psychiatric Association (Guideline R). This guideline provided a comprehensive description of the major features of treatment (e.g., case management, family interventions, rehabilitation, pharmacotherapy, and housing) and noted the importance of the same clinicians treating both the SMI and SUD. Overall, these recommendations are consistent with the broader literature on comprehensive and integrated treatment for this population (Drake et al., 1998, 2001). It should be noted that the treatment guideline for bipolar disorder, also authored by the American Psychiatric Association 
(Guideline J), did not contain any treatment recommendations regarding SUDs. This is a surprising finding, given the evidence suggesting that the rates of co-occurring alcohol and drug problems among persons with bipolar disorder are at least equal to or greater than the rates among persons with schizophrenia (Robins and Regier, 1991).

The second guideline to address treatment targeted substance use disorders with cooccurring psychiatric disorders (Guideline B). This is a comprehensive treatment guideline that contains screening suggestions, essential components of treatment (e.g., psychoeducation, double trouble groups, and community-based dual recovery mutual self-help groups), and treatment strategies (e.g., motivational interviewing, contingency management, relapse prevention, and assertive community treatment). This guideline also corresponds to a larger treatment manual provided by the Center for Substance Abuse Treatment (2005).

The majority of the guidelines targeting co-occurring disorders were intended for a multidisciplinary audience of service providers. This reflects the wide recognition that treating SUDs, SMIs, and these conditions as they co-occur requires coordination with many different provider types. However, the outcomes targeted by the guidelines were generally restricted to the primary focus of the single disorder, even though the assessment and/or treatment issues addressed co-occurring disorders. This suggests that many of these guidelines have limited utility for addressing the full range of problems and needs that are commonly encountered among persons with co-occurring disorders.

\section{Limitations and Generalizability}

This systematic review was restricted to guidelines archived on the NGC. This excluded a potentially large number of proprietary and nonproprietary guidelines that are available in print and electronically. Thus, the generalizability of this study is limited. Additionally, it was beyond the scope of this study to examine the quality and consistency of the recommendations contained in the guidelines against the extant literature. Despite these limitations, it is important to emphasize that the NGC remains as one of the largest (or the largest) data base that provides readily obtainable guidelines from major organizations that are free.

\section{Conclusions}

Treatment guidelines can play an important role in implementing evidence-based practices and changing provider practice patterns. Two guidelines that provide very specific information for treating co-occurring disorders were located. Although the current guidelines are limited, the NGC provides an infrastructure that makes guidelines widely available without charge. Additional efforts are needed to improve existing guidelines to better address co-occurring disorders. Without such guidelines, practitioners may fail to screen for and identify the presence of co-occurring SUDs and SMIs. Furthermore, in addition to screening, comprehensive empirically based treatment guidelines are necessary to inform practitioners of integrated treatment methods. As existing research suggests, outcomes for primary presenting disorders are likely to be improved through proper screening and treatment (Baethge et al., 2005; Haywood et al., 1995; Mangrum, Spence, and Lopez, 2006; Sacks, McKendrick, Sacks, Banks, and Harle, 2007). Additional research is also needed to better understand and overcome barriers related to the implementation of treatment guidelines and other forms of evidence-based practice (see Grimshaw, Eccles, and Tetroe, 2004). 


\section{Declaration of Interest}

The authors report no conflict of interest. The authors alone are responsible for the content and writing of this paper.

\section{RÉSUMÉ}

Les directives de pratique sont des outils importants pour améliorer la réalisation des pratiques à base d'évidence et pour réduire le désaccord inconvenant des approches actuelles de traitement. Cette étude a examiné le degré auquel les directives visées au traitement des assuétudes à la drogue ou aux maladies mentales sérieuses abordent le traitement des problèmes coexistants. Les directives archivées par le Centre d'Information National des Directives ont été répertoriées en décembre 2007 et analysées. Dix-neuf directives pertinentes ont été identifiées, et 11 d'entre elles ont inclus des recommandations concernant l'évaluation et/ou le traitement des problèmes coexistants. Aucune des directives faisant des recommandations pour le traitement des problèmes coexistants n'a inclus de résultats qui ont clairement visé à la fois les assuétudes à la drogue et les troubles mentaux. Les limitations et les implications de cette étude sont notées.

Mots clés : Directives de traitement, diagnostic double, problèmes coexistants

\section{RESUMEN}

Las pautas de práctica son herramientas importantes para mejorar la entrega de prácticas fundadas en pruebas y para reducir la variación inapropiada que existe en las métodos actuales. Ésta investigación examinó hasta qué punto las pautas dirigidas al tratamiento de la drogadicción o de la enfermedad mental consideran el tratamiento de trastornos coexistentes. Las pautas archivadas por el Centro de Información Nacional para las Pautas fueron fueron recuperadas en diciembre del 2007 y analizadas. Diecinueve pautas pertinentes fueron identificadas, y once incluyeron recomendaciones sobre la evaluación y/o tratamiento de los trastornos coexistentes. Ninguna de las pautas con recomendaciones para el tratamiento de los trastornos coexistentes incluyó resultados que se dirigieron directamente a tanto la drogadicción como las enfermedades mentales. Las limitaciones e implicaciones de esta investigación son notadas.

Palabras Claves: Pautas de práctica, diagnostico doble, trastornos coexistentes

\section{THE AUTHORS}

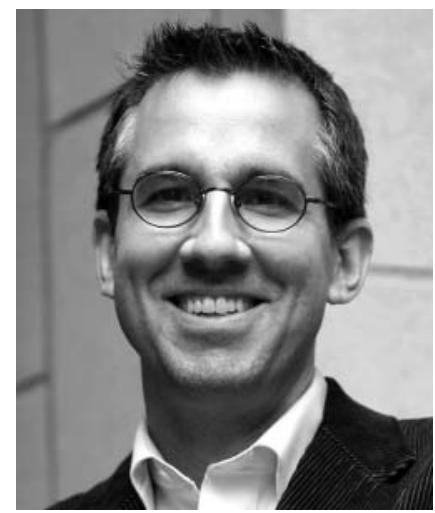

Brian E. Perron, PhD, is an Assistant Professor of Social Work at the University of Michigan. He studies services for persons with substance use disorders and psychiatric disorders, with an emphasis on their co-occurrence. The focus of his work involves issues related to treatment process, treatment utilization, and quality of care. Dr. Perron's training was funded by the National Institute of Mental Health and National Institute on Drug Abuse. He currently teaches social work courses on the diagnosis and treatment of substance use and psychiatric disorders. Prior to his doctoral training, Dr. Perron worked as a clinical social worker. 

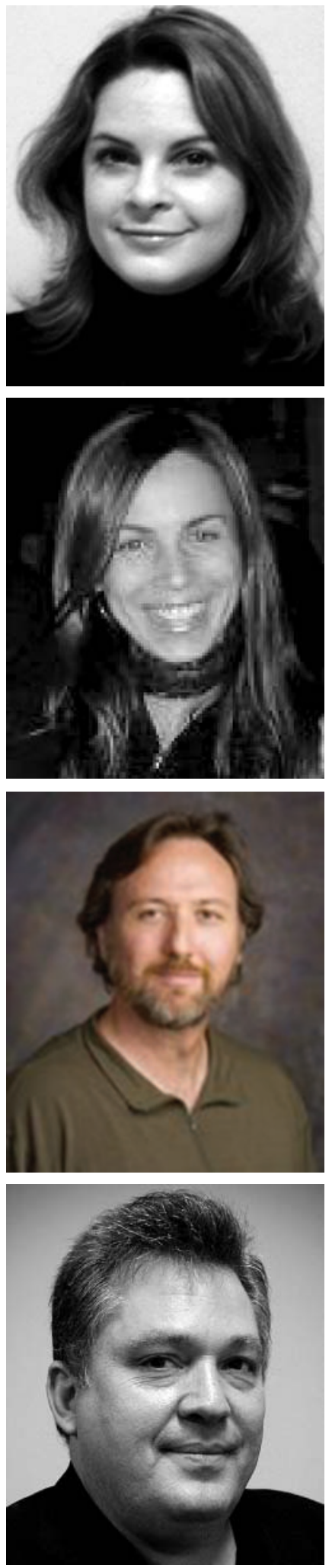

Matthew O. Howard, $\mathrm{PhD}$, is currently Frank A. Daniels Distinguished Professor of Human Services at the University of North Carolina at Chapel Hill. Formally, he was Professor of Social Work and Psychiatry at the University of Michigan. Dr. Howard has published 125 articles and serves on the editorial boards of Social Work Research, Research on Social Work Practice, Journal of Social Work and Public Health, American Indian and Alaska Native Mental Health Research, Journal of Evidence-Based Social Work, and Journal of Studies on Alcohol. He was the Editor of the Journal of Social Services Research, and presently is a Consulting Editor for the Journal of Social Work Education and Health and Social Work, and regu-

larly reviews for Psychosomatic Medicine, Drug and Alcohol Dependence, and many other 
journals. Dr. Howard reviews mental health texts for the Guilford, Allyn and Bacon, Sage, Lyceum, and McGraw-Hill publication houses. He has served on three NIH ad hoc grant review study sections, and has received three grants from the National Institute on Drug Abuse.

\section{Glossary}

Co-occurring disorders: "Co-occurring disorders" in this study refer to the simultaneous presentation of a substance use disorder and a serious mental illness. This usage is synonymous with other commonly used terms such as "dual diagnosis," "dual disorders," "co-morbidity," and "coexisting disorders."

Treatment guidelines: "Treatment guidelines" are systematically compiled statements of empirically tested knowledge and recommended practices designed to help practitioners and clients select appropriate interventions for specific clinical circumstances.

\section{References}

American Psychiatric Association. (2000). Diagnostic and statistical manual of mental disorders (4th, text revised ed.). Washington, DC: APA.

Baethge, C., Baldessarini, R. J., Khalsa, H. M., Hennen, J., Salvatore, P., Tohen, M. (2005). Substance abuse in first-episode bipolar I disorder: indications for early intervention. The American Journal of Psychiatry, 162(5):1008-1010.

Brunette, M. F., Mueser, K. T., Drake, R. E. (2004). A review of research on residential programs for people with severe mental illness and co-occurring substance use disorders. Drug and Alcohol Review, 23(4):471-481.

Center for Substance Abuse Treatment. (2005). Substance abuse treatment for persons with cooccurring disorders. Treatment improvement protocol (TIP) series 42. Rockville, MD: Substance Abuse and Mental Health Services Administration.

Drake, R. E., Essock, S. M., Shaner, A., Carey, K. B., Minkoff, K., Kola, L. (2001). Implementing dual diagnosis services for clients with severe mental illness. Psychiatric Services, 52(4):469-476.

Drake, R. E., Mercer-McFadden, C., Cueser, K. T., McHugo, G. J., Bond, G. R. (1998). Review of integrated mental health and substance abuse treatment for patients with dual disorders. Schizophrenia Bulletin, 24(4):589-608.

Drake, R. E., Mueser, K. T., Brunette, M. F., McHugo, G. J. (2004). A review of treatments for people with severe mental illnesses and co-occurring substance use disorders. Psychiatric Rehabilitation Journal, 27(4):360-374.

Ducharme, L. J., Knudsen, H. K., Roman, P. M. (2006). Availability of integrated care for co-occurring substance abuse and psychiatric conditions. Community Mental Health Journal, 42(4):363-375.

Dumaine, M. L. (2003). Meta-analysis of interventions with co-occurring disorders of severe mental illness and substance abuse: implications for social work practice. Research on Social Work Practice, 13(2):142-165.

Eddy, D. M. (1996). Clinical decision-making. Sudbury, MA: Jones and Bartlett.

Epstein, J., Barker, P., Vorburger, M., Murtha, C. (2004). Serious mental illness and its co-occurrence with substance use disorders, 2002. Rockville, MD: Office of Applied Studies, SAMHSA.

Grimshaw, J., Eccles, M., Tetroe, J. (2004). Implementing clinical guidelines: current evidence and future implications. The Journal of Continuing Education in the Health Professions, 24(Suppl 1):S31-S37.

Grimshaw, J. M., Shirran, L., Thomas, R., Mowatt, G., Fraser, C., Bero, L. (2001). Changing provider behavior: an overview of systematic reviews of interventions. Medical Care, 8(Supp 12):I12-I145.

Grimshaw, J. M., Thomas, R. E., MacLennan, G., Fraser, C., Ramsay, C. R., Vale, L. (2004). Effectiveness and efficiency of guideline dissemination and implementation strategies. Health Technology Assessment, 6:1-72. 
Hall, M. N., Amodeo, M., Shaffer, H. J., Vander Bilt, J. (2000). Social workers employed in substance abuse treatment agencies: a training needs assessment. Social Work, 45(2):141-155.

Haywood, T. W., Kravitz, H. M., Grossman, L. S., Cavanaugh, J. L., Jr., Davis, J. M., Lewis, D. A. (1995). Predicting the "revolving door" phenomenon among patients with schizophrenic, schizoaffective, and affective disorders. The American Journal of Psychiatry, 152(6):856861.

Howard, M. O., Jensen, J. M. (1999). Clinical practice guidelines: should social work develop them? Research on Social Work Practice, 9:283-301.

Institute of Medicine. (2006). Improving the quality of health care for mental and substance use conditions. Washington, DC: National Academy of Sciences.

Lincoln, A. K., Liebschutz, J. M., Chernoff, M., Nguyen, D., Amaro, H. (2006). Brief screening for co-occurring disorders among women entering substance abuse treatment. Journal of Substance Abuse Treatment, Prevention, and Policy, 1:1-26.

Mangrum, L. F., Spence, R. T., Lopez, M. (2006). Integrated versus parallel treatment of co-occurring psychiatric and substance use disorders. Journal of substance abuse treatment, 30(1):79-84.

Mark, T. L. (2003). The costs of treating persons with depression and alcoholism compared to depression alone. Psychiatric Services, 54(8):1095-1097.

Mark, T. L., Coffey, R. M., King, E., Harwood, H., McKusick, D., Genuardi, J. (2000). Spending on mental health and substance abuse treatment, 1987-1997. Health Affairs, 19(4):108-120.

National Advisory Mental Health Council. (1999). Bridging sciences and service: a report by the national advisory mental health council's clinical treatment and services research workgroup. Rockville, MD: NIMH.

National Institute of Drug Abuse. (2003). Report of the blue ribbon task force on the health services research at the national institute on drug abuse. Rockville, MD: NIDA.

National Institute of Mental Health. (2001). The impact of mental illness on society. Rockville, MD: NIMH.

President's New Freedom Commission on Mental Health. (2002). Achieving the promise: transforming mental health care in America. Retrieved March 1, 2008, from http://www.mentalhealthcommission.gov/ed Rockville, MD: SAMHSA.

Proctor, E. K., Rosen, A. (2003). Developing practice guidelines for social work interventions. In The structure and function of social work practice guidelines (pp. 108-127). New York: Columbia University.

RachBeisel, J., Scott, J., Dixon, L. (1990). Co-occurring severe mental illness and substance use disorders: a review of recent research. Psychiatric Services, 50(11):1427-1434.

Robins, L. N., Regier, D. A. (1991). Psychiatric disorders in America: the epidemiologic catchment area study. New York: Free Press.

Rosen, A., Proctor, E. K. (2003). Developing practice guidelines for social work interventions. In Practice guidelines and the challenge of effective practice (pp. 1-14). New York: Columbia University.

Sacks, S., McKendrick, K., Sacks, J. Y., Banks, S., Harle, M. (2007). Enhanced outpatient treatment for co-occurring disorders: main outcomes. Journal of Substance Abuse Treatment, 34(1):112-122.

Stinson, F. S., Grant, B. F., Dawson, D. A., Ruan, W. J., Huang, B., Saha, T. (2005). Comorbidity between DSM-IV alcohol and specific drug use disorders in the United States: results from the national epidemiologic survey on alcohol and related conditions. Drug and Alcohol Dependence, 80:105-116.

Substance Abuse and Mental Health Services Administration. (2002). Report to Congress on the prevention and treatment of co-occurring substance abuse disorders and mental disorders: Executive summary. Rockville, MD: SAMHSA.

Swartz, J. A., Lurigio, A. J. (2006). Screening for serious mental illness in populations with cooccurring substance use disorders: performance of the K6 scale. Journal of substance abuse treatment, 31(3):287-296.

US Department of Health and Human Services. (1999). Mental health: a report to the surgeon general, executive summary. Rockville, MD: USDHHA, SAMHSA, CMHS, NIH, NIMH. 
US Department of Health and Human Services. (2000). Healthy people 2010. with understanding and improving health and objectives for improving health (Vol. 2, 2nd ed.). Washington, DC: US Government Printing Office.

Walker, R. D., Howard, M. O., Lambert, M. D., Suchinsky, R. T. (1994). Medical practice guidelines. Western Journal of Medicine, 161:39-44.

Walker, R. D., Howard, M. O., Walker, R. D., Lambert, M. D., Suchinsky, R. T. (1995). Practice guidelines in the addictions: recent developments. Journal of Substance Abuse Treatment, 12(2): 63-73.

Watkins, K. E., Burnam, A., Kung, F. Y., Paddock, S. (2001). A national survey of care for persons with co-occurring mental and substance use disorders. Psychiatric Services, 52(8):1062-1068.

\section{Appendix}

Treatment Guidelines Included in a Systematic Review

Abbreviation Full citation

\section{Substance use disorders}

B. CSAT (2005)

C. CSAT (2004a)

D. CSAT (2004b)

E. MQIC (2003)

F. NYSDH (2005)

Work Group on Substance Use Disorders, Kleber HD, Weiss RD, Anton RF, Rounsaville BJ, George TP, Strain EC, Greenfield SF, Ziedonis DM, Kosten TR, Hennessy G, O'Brien CP, Connery HS, American Psychiatric Association Steering Committee on Practice Guidelines, McIntyre JS, Charles SC, Anzia DJ, Nininger JE, Cook IA, Summergrad P, Finnerty MT, Woods SM, Johnson BR, Yager J, Pyles R, Lurie L, Cross CD, Walker RD, Peele R, Barnovitz MA, Gray SH, Shemo JP, Saxena S, Tonnu T, Kunkle R, Albert AB, Fochtmann LJ, Hart C, Regier D. Treatment of patients with substance use disorders (2nd ed.). American Psychiatric Association, Washington, DC. Am J Psychiatry (2006 Aug); 163(8 Suppl):5-82.

Center for Substance Abuse Treatment. (2005). Substance abuse treatment for persons with co-occurring disorders. Rockville, MD: Substance Abuse and Mental Health Services Administration (SAMHSA).

Center for Substance Abuse Treatment. (2004). Substance abuse treatment: group therapy. Rockville, MD: Substance Abuse and Mental Health Services Administration. Center for Substance Abuse Treatment. (2004). Substance abuse treatment and family therapy. Rockville, MD: Substance Abuse and Mental Health Services Administration. Michigan Quality Improvement Consortium. (2005, Aug). Screening and management of substance use disorders. Southfield,(MI: Michigan Quality Improvement Consortium. New York State Department of Health. (2005, Mar). Screening and ongoing assessment for substance use. New York, NY: New York State Department of Health. 


\begin{tabular}{cl}
\hline \multicolumn{1}{c}{ Abbreviation } & \multicolumn{1}{c}{ Full citation } \\
\hline G. NYSDH (2006) & $\begin{array}{l}\text { New York State Department of Health. (2006, Oct). Working } \\
\text { with the active user. New York, NY: New York State } \\
\text { Department of Health. } \\
\text { Peters RH, Wexler HK. (2005 Sep 12). Substance abuse } \\
\text { treatment for adults in the criminal justice system. Rockville, } \\
\text { MD: Substance Abuse and Mental Health Services }\end{array}$ \\
& $\begin{array}{l}\text { Administration (SAMHSA). } \\
\text { Screening and behavioral counseling interventions in primary } \\
\text { care to reduce alcohol misuse: recommendations statement. } \\
\text { I. USPSTF (2004) }\end{array}$ \\
& Ann Intern Med (2004, Apr 6);140(7):554-556.
\end{tabular}

\section{Bipolar disorder} J. APA (2002)

\section{Major depressive disorder}

K. AMDA (2003)

L. APA (2000)

M. ICSI (2004)

N. KPCMI (2006)

O. MQIC (2006)

P. UMHS (2004)

Q. USPSTF (2002)

Schizophrenia/psychoses

R. APA (2004)

S. VA/DoD (2004)
Practice guideline for the treatment of patients with bipolar disorder (revision). Am J Psychiatry (2002 Apr); 159(4 Suppl):1-50.

American Medical Directors Association (AMDA). (2003). Depression. Columbia, MD: American Medical Directors Association (AMDA).

American Psychiatric Association practice guideline for the treatment of patients with major depressive disorder. Am J Psychiatry (2000 Apr);157(4 Suppl):1-45.

Institute for Clinical Systems Improvement (ICSI). (2006, May). Major depression in adults in primary care.

Bloomington, MN: Institute for Clinical Systems Improvement (ICSI).

Kaiser Permanente Care Management Institute. (2006, Mar). Depression clinical practice guidelines. Oakland, CA: Kaiser Permanente Care Management Institute.

Michigan Quality Improvement Consortium. (2006, Jan). Management of adults with major depression. Southfield, MI: Michigan Quality Improvement Consortium.

University of Michigan Health System. (2005 Oct).

Depression. Ann Arbor, MI: University of Michigan Health System.

US Preventive Services Task Force. Screening for depression: recommendations and rationale. Ann Intern Med (2002, May 21);136(10):760-764.

American Psychiatric Association. (2004, Feb). Practice guideline for the treatment of patients with schizophrenia (2nd ed.). Arlington, VA: American Psychiatric Association. Veterans Administration, Department of Defense. (2004, May). Management of persons with psychoses. Washington, DC: Department of Veteran Affairs. 